\title{
Effects of freezing and soil drought on the geochemical fractionation of americium in Fluvisol and Cambisol soils from Bulgaria
}

\author{
Petya Kovacheva, Desislava Yovkova, Boian Todorov, Rumyana Djingova \\ Faculty of Chemistry and Pharmacy, University of Sofia, Sofia
}

\begin{abstract}
Extreme changes of environmental conditions can alter the soil properties and influence the migration ability and bioavailability of pollutants. Elucidation of the effects of the extreme weather conditions, such as sharp temperature change, drought and floods, on the fractionation of radionuclides in different soil types is especially important for adequate risk assessment after radioactive contamination. The effects of short-term and prolonged freezing and soil drought on the geochemical fractionation of americium in two soil types (Fluvisol and Cambisol, classified according to the World Reference Base for Soil Resources/FAO) from Bulgaria were studied. The changes of the physico-chemical forms of ${ }^{241} \mathrm{Am}$ after storage under different conditions were determined by the sequential extraction procedure and gamma-spectrometric measurements. The impact of the sharp temperature decrease and drought on the association of the radionuclide with the various soil phases was considered in terms of the soil characteristics. The results showed that the risk of increased mobility and bioavailability of americium in the loamy-sand soil with acidic $\mathrm{pH}$ and very low cation exchange capacity (CEC) exists under the examined extreme environmental conditions. The soil with sand-loam texture tended to immobilize americium after freeze and drought storage.
\end{abstract}

Key words: americium, geochemical fractionation, soil characteristics, freezing, soil drought

\section{Introduction}

Studies of the migration, biotransformation and bioaccumulation of radioactive elements in terrestrial ecosystems are of special interest for assessment of their transfer along the trophic chain and radiological and toxicological effects. Numerous investigations show that the distribution and bioavailability of radionuclides in nature are a function of their chemical fractionation in the soils

Addresses: P. Kovacheva, D. Yovkova, B. Todorov, R. Djingova: "St. Kliment Ohridski", 1, J. Bourchier Blvd., Sofia 1164, Bulgaria, e-mail: PKovacheva@wmail.chem.uni-sofia.bg

Received: Marc 22, 2013; accepted: May 17, 2013 
(e.g. Schultz et al. 1998; Rao et al. 2008), which depends both upon their physicochemical forms and the soil characteristics (Igwe et al. 2005). The long-term differences of the environmental conditions were found to cause redistribution of the radionuclides within the various soil fractions due to changes of the $\mathrm{pH}$, the redox potential, destruction of the organic matter, leaching and ion-exchange (Koch-Steidl and Pröhl 2001). Sharp variations of environmental temperature can influence the amount and the rate of radionuclide adsorption to soil particles. Almas et al. (1999) reported an increase of the fixation of ${ }^{109} \mathrm{Cd}$ and ${ }^{65} \mathrm{Zn}$ tracers to soil, caused by temperature increase; however, the addition of organic matter decreased this effect. Marion (1995) published a review of the interactions between the freeze-thaw processes and soil chemistry. Freezing effects on the aggregate stability in soils have been studied by Lehrsch et al. (1991), who found that it depends on the soil texture, organic matter and water content. MüllerLupp and Bölter (2003) investigated the effect of soil freezing on physical and microbiological properties of permafrost-affected soils and reported that cyclic freezing and thawing provoked different changes, depending on the soil composition. According to Borch et al. (2010) increased precipitation or flooding is expected to lead to a potential change in soil redox conditions. Soil drought in arid regions may also lead to changes of the main soil characteristics, such as $\mathrm{pH}$ and cation exchange capacity, which thus affects the speciation of the radionuclides and cause changes of their migration ability and bioavailability.

Microorganisms directly and indirectly influence the speciation of elements in the soil (Roussel-Debet et al. 2005; Borch et al. 2010) and therefore are another important factor to be considered when the mobility of the radionuclides and their fate in the environment are to be assessed. Since microbiological activity depends on the environmental conditions and changes under different temperature and soil moisture conditions (Brady and Weil 2002) it is logical to expect that the changes of temperature and soil moisture affect the microbiologically-caused modifications of the fractionation of radionuclides in the soils.

However, the complex interaction between a radionuclide in a certain chemical state and a soil with specific characteristics is difficult to predict in cases of sharp variations of climatic parameters. Elucidation of the effects of the extreme weather conditions, such as sharp temperature change, drought and floods, on the fractionation of radionuclides is especially important in order to perform adequate risk assessment after radioactive contamination. Therefore the impact of two of the main climatic parameters, namely temperature and soil moisture, on the geochemical fractionation of radionuclides in the soil is worth studying.

We recently studied the influence of the two weeks freezing on the migration ability and bioavailability of natural and technogenic radionuclides after their entrance in Chernozem soil (Kovacheva and Djingova, in press). Our investigation showed that the sharp temperature decrease and subsequent thawing increased the potential mobility of radiocobalt, radiocesium, radium and 
thorium and did not have significant impact on the fractionation of americium and uranium. The changes of the physico-chemical fractionation of americium, thorium and uranium in Chernozem soil after sharp temperature change and soil drought for three month were also studied (Kovacheva et al., in press). The data showed that continuous freezing increased the potentially mobile forms of americium and thorium but had the opposite effect on uranium. The prolonged soil drought led to redistribution of uranium between the soil phases and caused its immobilization. The subsequent warming of the frozen soils caused immobilization of americium and thorium and increased the potential mobility of uranium. The warming and enhanced humidity of the dry soil led to immobilization of americium and redistribution of uranium between the soil phases. Considering the influence of the soil characteristics on the fractionation of the radionuclides and their behavior in nature, the impact of sharp changes of the environmental conditions on different soil types needs to be investigated.

The present study aimed to examine the effects of the sharp drop of the environmental temperature and the soil drought on the geochemical forms of ${ }^{241} \mathrm{Am}$, depending on soil characteristics. The paper presents the changes of the geochemical fractionation of americium, driven by freezing and drought and continuing one and five months after its entrance in two soil types: Fluvisol and Cambisol (FAO 2006).

\section{Materials and methods}

Description of the soils and conditions of storage

Two types of soils with different properties (Cambisol and Fluvisol) were chosen to study the change of the fractionation of ${ }^{241} \mathrm{Am}$, under different temperature and soil humidity conditions. The soil sampling was from the surface soil layer $(0-5 \mu \mathrm{m})$. The single samples were united in a bulk sample, air dried and cleaned of plant impurities (roots, leaves), followed by sieving through $2 \mathrm{~mm}$-sieves and homogenization.

The general characteristics of the studied soils, including $\mathrm{pH}$ in $\mathrm{H}_{2} \mathrm{O}$ and in 0.1 $\mathrm{M} \mathrm{KCl}, \mathrm{CEC}$ (meq/100 g), relative content of sand, silt, clay and humus and the total concentrations of Al, Fe and Mn determined by ICP-MS (PerkinElmer DRCe) are presented in Table 1 . The total digestion of the soil samples was performed as follows: $2 \mathrm{ml} \mathrm{HNO}_{3}$ and $2 \mathrm{ml} \mathrm{HF}$ were added to $0.1 \mathrm{~g}$ soil and left for 24 hours, followed by microwave (MW) digestion. Afterwards $1 \mathrm{ml} \mathrm{HF}$ was added and a second MW digestion was performed. After addition of $5 \mathrm{ml} \mathrm{H}_{3} \mathrm{BO}_{3}$ and $\mathrm{MW}$ the samples were diluted to $50 \mathrm{ml}$ and stored at $4{ }^{\circ} \mathrm{C}$. Before analysis additional dilution at 1:50 was carried. All the reagents were Suprapure grade materials.

To $1 \mathrm{~kg}$ of each soil type were added $500 \mathrm{ml}$ distilled $\mathrm{H}_{2} \mathrm{O}$ and $1 \mathrm{ml}^{241} \mathrm{Am}^{3+}$ in nitrate form (Eurostandard CZ) and $\mathrm{pH} 4$, with a total activity of $58 \pm 1 \mathrm{kBq}$. The contaminated soils were homogenized and conditioned during 7 days at $20 \pm 2$ ${ }^{\circ} \mathrm{C}$ and soil moisture $40-55 \%$, w/w. Afterwards the contaminated soil samples 
Table 1

General characteristics of the investigated soils

\begin{tabular}{|l|l|l|l|l|l|l|l|l|l|l|}
\hline \multirow{2}{*}{$\begin{array}{c}\text { Soil type/ } \\
\text { Texture class }\end{array}$} & \multicolumn{2}{|c|}{ Soil pH } & $\begin{array}{c}\mathrm{CEC} \\
(\mathrm{meq} / 100 \mathrm{~g})\end{array}$ & $\begin{array}{c}\% \\
\text { sand }\end{array}$ & $\begin{array}{c}\% \\
\text { silt }\end{array}$ & $\begin{array}{c}\% \\
\text { clay }\end{array}$ & $\begin{array}{c}\% \\
\text { humus }\end{array}$ & $\begin{array}{c}\mathrm{Al} \\
(\mu \mathrm{g} / \mathrm{g})\end{array}$ & $\begin{array}{c}\mathrm{Fe} \\
(\mu \mathrm{g} / \mathrm{g})\end{array}$ & $\begin{array}{c}\mathrm{Mn} \\
(\mu \mathrm{g} / \mathrm{g})\end{array}$ \\
\hline $\begin{array}{l}\text { Fluvisol/ } \\
\text { Loamy sand }\end{array}$ & 5.2 & 5.5 & 5.89 & 78.05 & 20.16 & 1.79 & 2.65 & 27500 & 14000 & 580 \\
\hline $\begin{array}{l}\text { Cambisol/ } \\
\text { Sandy loam }\end{array}$ & 7.4 & 7.6 & 31.1 & 61.58 & 33.23 & 5.19 & 2.03 & 38500 & 25300 & 570 \\
\hline
\end{tabular}

were divided into three equal parts and kept for five months under the following temperatures and soil moisture conditions:

- Condition set $1:+20 \pm 2{ }^{\circ} \mathrm{C}$ during the day and $14 \pm 3{ }^{\circ} \mathrm{C}$ during the night in open-air vessels in the laboratory. The sample was periodically watered and the soil moisture was varied from $30 \%$ to $50 \%, \mathrm{w} / \mathrm{w}$. The water status of the samples was examined by weighing.

- Condition set 2 (soil drought): $+20 \pm 2{ }^{\circ} \mathrm{C}$ during the day and $14 \pm 3{ }^{\circ} \mathrm{C}$ during the night in open-air vessels in the laboratory. Soil drought was achieved by heating of the soil up to $33^{\circ} \mathrm{C}$ by using a heating lamp ( $250 \mathrm{~V}, \lambda>400 \mathrm{~nm}$ ), placed at $20 \mathrm{~cm}$ distance from the soil surface. The heating was performed for 6 hours/day during 7 days. The soil was kept air dry and its moisture varied from 0.8 to $2.2 \%, \mathrm{w} / \mathrm{w}$.

- Condition set 3 (freezing): $-18 \pm 1{ }^{\circ} \mathrm{C}$ and $40 \% \pm 1 \%$ soil moisture, $\mathrm{w} / \mathrm{w}$, achieved by use of closed plastic vessels in a freezer.

Soil subsamples with a weight of $100 \mathrm{~g}$ were taken after the first and the fifth month of storage and dried at $30^{\circ} \mathrm{C}$ for 24 hours. The specific activity of ${ }^{241} \mathrm{Am}$ in each subsample was determined by gamma-spectrometry and varied from 55 to $60 \mathrm{~Bq} / \mathrm{g}$. Three equal portions of $10 \mathrm{~g}$ each of dry subsamples were processed by the sequential extraction procedure as described below.

\section{Sequential extraction procedure}

The fractionation of ${ }^{241} \mathrm{Am}$ in the soil samples was studied by the sequential extraction procedure, proposed by Schultz et al. (1998) and recommended by NIST for fractionation of actinides in soils and sediments. Four extractive reagents: (1) distilled $\mathrm{H}_{2} \mathrm{O}$, (2) $5-6 \% \mathrm{NaOCl}$ (pH 7.5), (3) $1 \mathrm{M} \mathrm{CH}_{3} \mathrm{COONa}$ in $25 \%$ $\mathrm{CH}_{3} \mathrm{COOH}(\mathrm{pH} 4)$ and (4) $0.04 \mathrm{M} \mathrm{NH}_{2} \mathrm{OH} . \mathrm{HCl}(\mathrm{pH} 2)$, were used to determine, respectively: (1) water solubility, (2) association with organic matter, (3) binding or specific sorbing to the soil carbonates and (4) association with $\mathrm{Fe} / \mathrm{Mn}$ oxyhydroxide (sesquioxide) fractions.

The contents of ${ }^{241} \mathrm{Am}$ in the residual fraction were determined by the difference between their total radioactivity in the soil and the activity extracted by the four reagents. Supernatants were separated from the solid phase by 
centrifuging at $3000 \mathrm{rpm}$ at $20^{\circ} \mathrm{C}$ for $20 \mathrm{~min}$, followed by filtering through $0.2 \mu \mathrm{m}$ cellulose nitrate filters using vacuum-driven filtration.

\section{Measurement conditions}

The radioactivity of the solid samples and the leachants was determined using a HPGe Canberra 7221 detector (energy resolution 1.9 and efficiency $16 \%$ at 1332.5 $\mathrm{keV}$ ) coupled to a 16000-channel DSA-1000 analyzer. The spectra obtained were processed using Genie-2000 Basic Spectroscopy Software. The activity of ${ }^{241} \mathrm{Am}$ was measured by its gamma peak at $59.5 \mathrm{keV}$. Efficiency calibration was carried out using national standard radioactive solutions and standard samples, produced and standardized at the Institute for Nuclear Research and Nuclear Energy, Bulgarian Academy of Sciences. Accuracy and precision were verified by participation in IAEA round robin tests.

Dry soil samples with a weight of $50 \mathrm{~g}$ were prepared for measurement of the exact specific activity by pressing them into standard vessels with a volume of 50 $\mathrm{ml}$. The measured liquid samples had a volume of $50 \mathrm{ml}$. The determined optimal counting time used for the measurement of the solid samples was $10000 \mathrm{~s}$ and the liquid samples were measured for $30000 \mathrm{~s}$.

\section{Results and discussion}

The results of the physico-chemical fractionation of americium after storage under different conditions (as described above) are presented in Figs 1-4. The data are mean percent radionuclide in each fraction \pm standard uncertainty of triplicate determinations.

The effects of the soil drought (condition set 2) and freezing (condition set 3) of the two soil types on the geochemical fractionation of americium were evaluated by comparison with the data, obtained after storage at $14-20^{\circ} \mathrm{C}$ and $30-50 \%$ soil moisture (condition set 1).

\section{Effects in Fluvisol soil}

Figure 1 presents a comparison of the results after one month of storage of Fluvisol under condition sets $1-3$. About $60 \%$ of ${ }^{241} \mathrm{Am}$ was found in the residual fraction from condition set 1 . Practically no Am was detected in the water-soluble and oxide fractions.

The storage at soil drought caused a significant increase of the carbonate and sesquioxide-bound fraction of the radionuclide (Fig. 1), leading to triple decrease of its relative content in the residual. According to Wong et al. (2002) the carbonate-bound radionuclides, together with the exchangeable fraction, are considered as readily and potentially bioavailable. Hence the obtained results indicated raised potential mobility and biological availability of americium in 


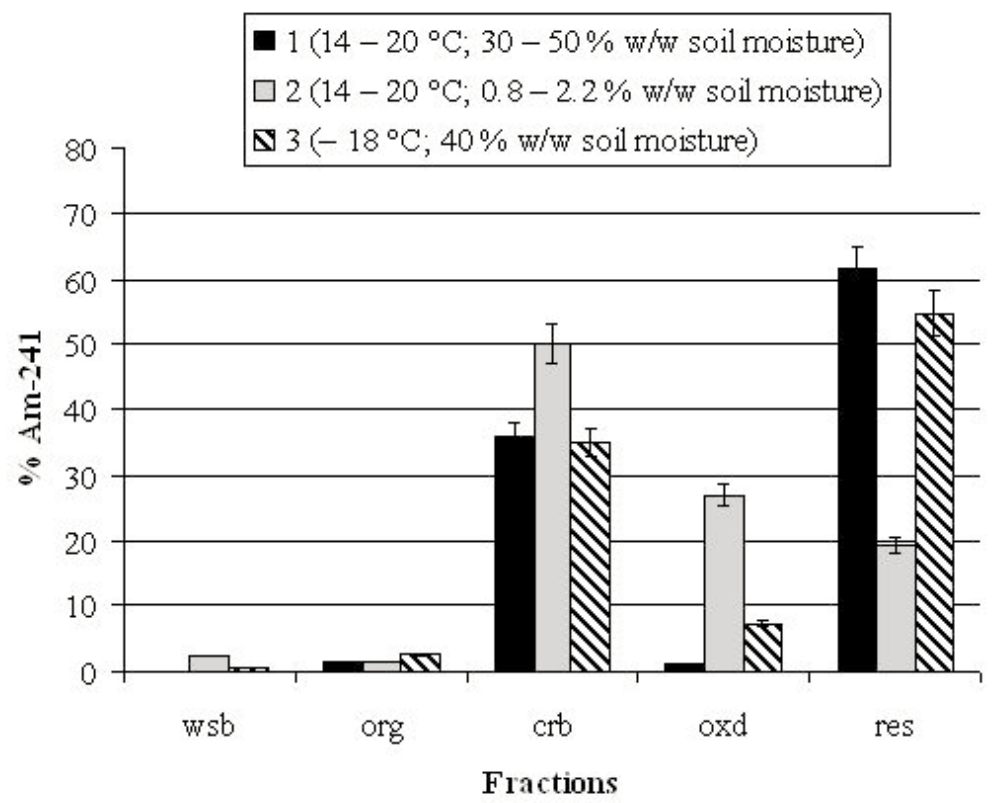

Fig. 1

Relative content of ${ }^{241} \mathrm{Am}(\%)$ in the various soil phases of Fluvisol after 1 month storage at condition sets 1-3 (wsb - water-soluble fraction, org - organic matter fraction, crb - carbonate bounded fraction, oxd - sesquioxide bounded fraction, res - residual fraction)

Fluvisol soil. At the $\mathrm{pH}$ range from 5.2 to 5.5 of the soil solution americium can exist as positively charged ions, such as $\mathrm{Am}^{3+}, \mathrm{Am}\left(\mathrm{CO}_{3}\right)_{\mathrm{x}}{ }^{3-2 \mathrm{x}}$ and $\mathrm{Am}(\mathrm{OH})_{\mathrm{x}}{ }^{3-\mathrm{x}}$, $\mathrm{AmSO}_{4}{ }^{+}, \mathrm{AmNO}_{3}{ }^{2+}, \mathrm{AmCl}^{2+}$, etc., the partial concentrations of which depend on the redox potential and the composition of the soil solution (Cantrell and Felmy 2012). Soil drought conditions, reached by slight evaporation of the soil solution, increases its concentration and is expected to cause salinization and alkalinization of the soil solution (Koch-Steidl and Pröhl 2001), facilitating sorption of the positively-charged americium ions on the carbonates and soil sesquioxides as well as co-precipitation as insoluble oxides, phosphates, silicates, etc. The present results showed that soil drought maintained for one month impeded the further inclusion of americium in the residual fraction and thus increased its potential mobility.

Freeze storage during one month had slight effects on the fractionation of americium in Fluvisol soil. An increase of the sesquioxide bounded radionuclide from $1 \%$ to $7 \%$, accompanied by respective decrease of its relative content in the residual fraction, was measured. The registered slight enhancement of the potentially mobile americium cannot be considered as a significant radiological hazard, since the Fe-Mn oxide, together with the organic/sulfide-bound forms, represent a relatively stable fraction under normal soil condition (Wong et al. 2002). 
Figure 2 presents the comparison of the results obtained for fractionation of americium in Fluvisol after 5 months storage under condition set 1-3. The comparison of the data in Figures 1 and 2 indicated that prolonged storage under condition set 1 had practically no effect on the geochemical fractionation of americium in the loamy-sand Fluvisol soil. Five months of continuous freezing and drought retained the tendency of increasing the potentially mobile forms of Am; however, redistribution of the radionuclide between the soil phases was established, similar for both conditions: increase of the organic-bound fraction of americium from $2-3 \%$ to $9 \%$ and decrease of the fraction associated with sesquioxides from 27 to $18 \%$ under soil drought conditions, and from 7 to $4 \%$ under freezing conditions. A slight increase of the carbonate-bound americium as a result of prolonged freezing was also observed. This led to the reduction of the relative content of americium in the residual fraction to $10 \%$, predicting enhanced potentially mobile forms. Such effects were not observed in the sample stored under condition set 1 , and therefore are to be ascribed to the changes in the soil properties provoked by the prolonged drought and freezing. The continuous

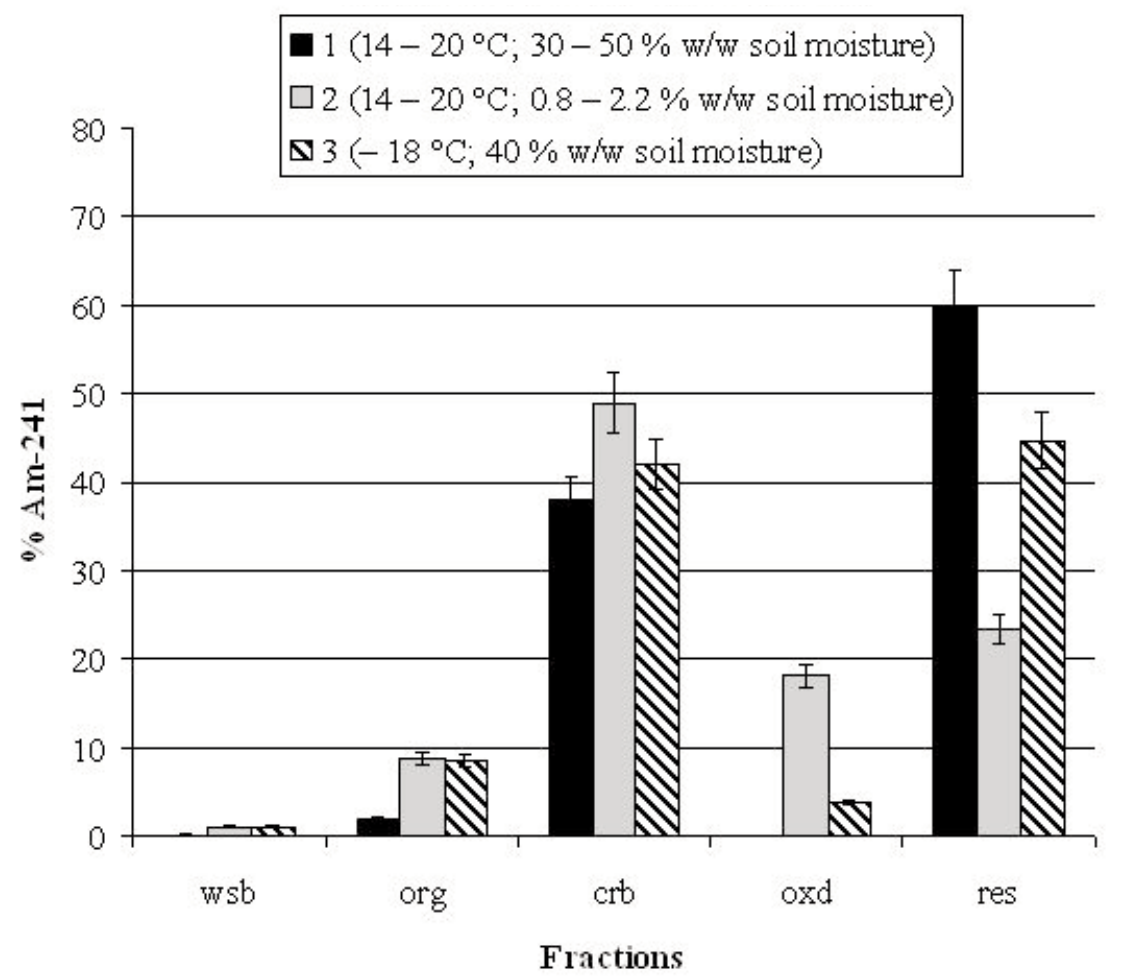

Fig. 2

Relative content of ${ }^{241} \mathrm{Am}(\%)$ in the various soil phases of Fluvisol after 5 months storage at condition sets 1-3 (wsb - water-soluble fraction, org - organic matter fraction, crb - carbonate bounded fraction, oxd - sesquioxide bounded fraction, res - residual fraction) 
storage of the loamy sand Fluvisol soil under the studied extreme environmental conditions led to an increase of the potentially mobile fraction of americium, as observed at the first month of conditioning. This effect was more pronounced after storage under soil drought conditions.

\section{Effects in Cambisol soil}

Figures 3 and 4 present the results from the fractionation of Am after 1 and 5 months storage under condition sets $1-3$. After one month storage under condition set $1 \mathrm{Am}$ is practically distributed between the carbonate and residual fractions (Fig. 3). The soil drought resulted in redistribution of the carbonatebound Am, leading to substantial increase of the oxide fraction. The Cambisol soil had a slightly alkaline $\mathrm{pH}$, which rose due to the increase of the soil solution concentration during evaporation, and facilitated the hydrolysis of americium. The higher content of clay and higher concentrations of $\mathrm{Fe}$ and $\mathrm{Al}$ in this soil contributed to higher sorption onto $\mathrm{Al}_{2} \mathrm{O}_{3}$ and $\mathrm{FeOOH}$, as reported by Alonso and Degueldre (2003).

Freezing conditions resulted in substantial increase of Am in the residual fraction and corresponding decrease of carbonate-bound Am. This effect can be ascribed to the oversaturation of the soil solution, enabling additional sorption or co-precipitation to poorly soluble compounds, like silicates, phosphates and oxycarbonates. With the rise of $\mathrm{pH}$ due to the increase of the soil solution concentration under freezing, more negatively-charged binding sites became available on mineral surfaces as a result of the deprotonation of the ampholytic surface hydroxyls. This facilitated the sorption of the positively-charged americium ions.

Similarly to condition set 1 , in practical terms the quantities of Am bound to oxides, organic and water soluble fractions were insignificant.

Figure 4 presents the results after 5 months of storage under condition set 1-3. Substantial redistribution of Am at storage condition set 1 in respect to 1 month storage (Fig. 3) was established. The residual bound Am has decreased approx. 4 times, resulting in an increase of organic and carbonate-bound Am. In contrast soil drought (condition set 2) decreased the potential mobility of Am, $62 \%$ of which was established in the residual fraction. The carbonate-bound Am was considerably reduced compared to its quantity at condition set 1 ; however, a slight increase of this fraction as a result of prolonged storage at soil drought conditions was detected. The water-soluble and oxide-bound Am was found to be below $1.5 \%$. The comparison to Fig. 3 showed that after 5 months storage, soil drought has led to an increase of organic-bound Am and a significant decrease of oxide-bound Am. Freezing also had a similar effect as soil drought, namely increasing the residual Am (compared to condition set 1), decreasing carbonatebound Am and increasing organic-bound Am in comparison to 1 month of storage. 


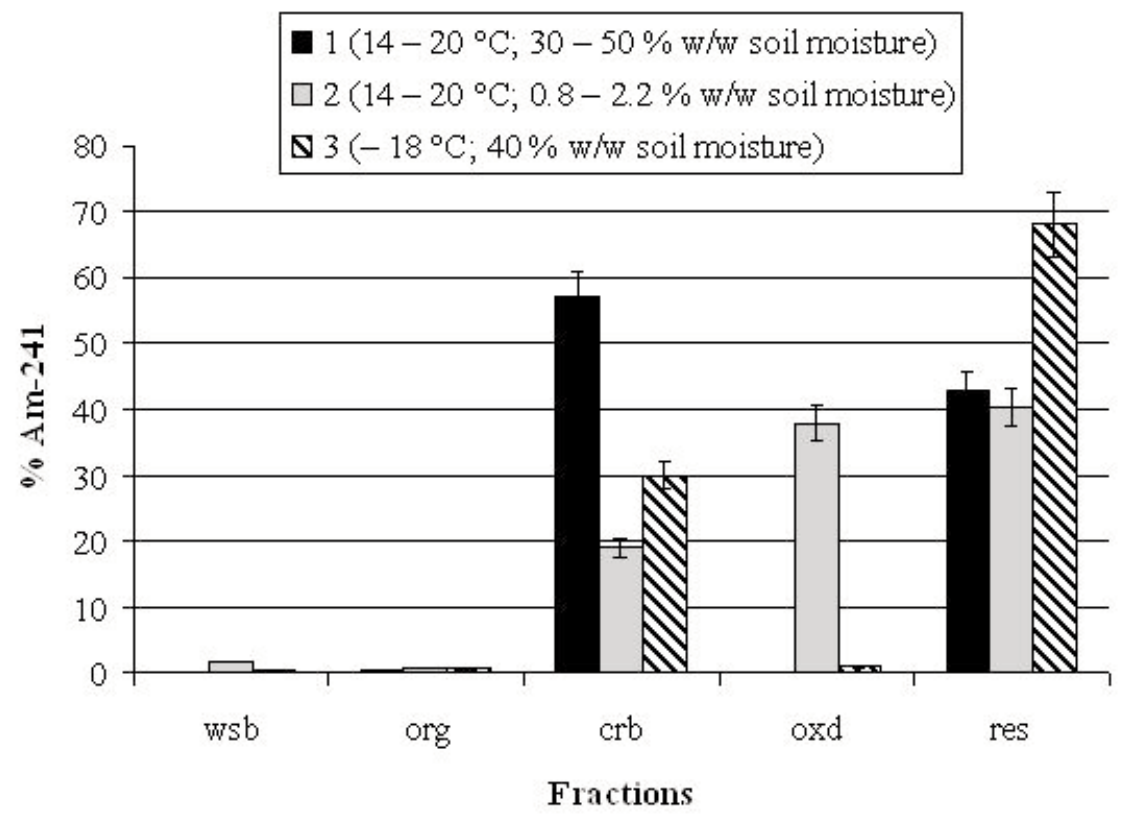

Fig. 3

Relative content of ${ }^{241} \mathrm{Am}(\%)$ in the various soil phases of Cambisol after 1 month storage at condition sets $1-3$ (wsb - water-soluble fraction, org - organic matter fraction, crb - carbonate bounded fraction, oxd - sesquioxide bounded fraction, res - residual fraction)

According to Marion (1995) the solute exclusion during ice formation led to supersaturated solutions and promoted precipitation of secondary minerals in soil and altered solution-phase compositions (which may promote the dissolution of primary minerals), which apparently resulted in increased inclusion of americium in the residual fraction of the Cambisol soil. The increase of the organic-bound americium in Cambisol and its significantly decreased content in the residual fraction with time (comparing Figs 3 and 4) can be due to microbiological activity, which provoked production of organic acids and complexing agents leading to leaching of the radionuclide, bound to silicates, phosphates, sulfides, carbonates, oxides, etc. Another explanation of the observed effects might be the influence of the sharp temperature drop or soil drought on the soil aggregates. The expansion or contraction of the soil particles due to freezing or drying might have affected the aggregate stability, causing dispersion of the soil particles and increasing the specific soil surface. This in turn provoked an increased interaction between the colloids and soil solution and favored a redistribution of the radionuclide at such low concentration in the case of subsequent thawing or wetting. Thus, the observed differences in the effects of freezing and soil drought on the fractionation of americium in the two soil types might be ascribed to the difference in their texture (see Table 1). While Fluvisol 


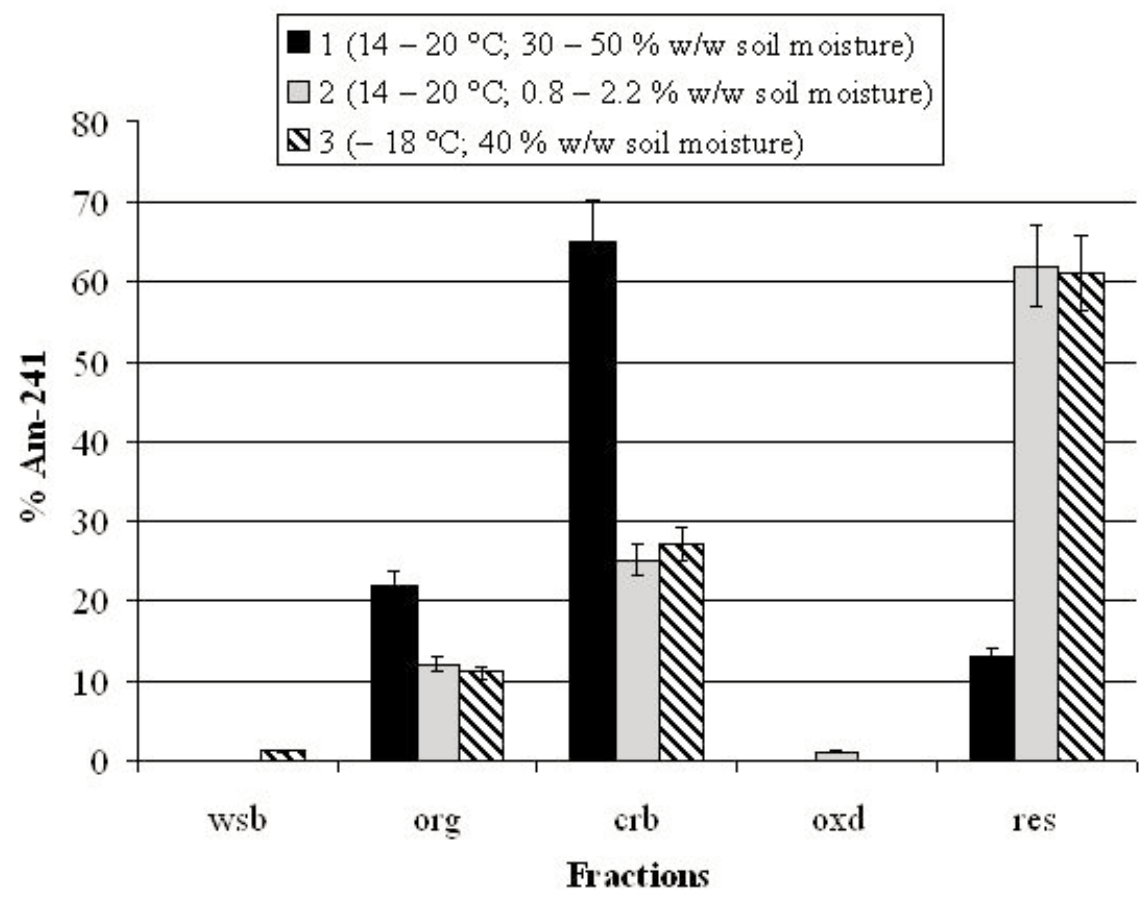

Fig. 4

Relative content of ${ }^{241} \mathrm{Am}(\%)$ in the various soil phases of Cambisol after 5 months storage at condition sets 1-3 (wsb - water-soluble fraction, org - organic matter fraction, crb - carbonate bounded fraction, oxd - sesquioxide bounded fraction, res - residual fraction)

soil has a predominating sand content and only $1.8 \%$ clay, the Cambisol soil contained a nearly three times higher percentage of clay, which favored stabilization of soil aggregates.

The prolonged storage at soil drought conditions had different effects upon the studied soil types, probably due to the increased cementing effect of the clay in Cambisol soil, which restricted soil aeration and led to changes of microbiological activity, provoking redistribution of americium between the soil fractions. Additional investigations with soils of different texture are needed to confirm the above-mentioned assumptions.

\section{Conclusions}

The present investigation indicated the soil drought and freezing have different effects on the geochemical fractionation of americium strongly depending on the soil characteristics. The obtained results can be summarized as follows: 
- One month storage at soil drought conditions significantly increased the potential mobility of americium in Fluvisol soil and caused redistribution of Am (from carbonate to oxide fraction) in the sandy loam Cambisol soil.

- Freeze storage for one month increased americium immobilization in Cambisol and had only a slight effect on its fractionation in Fluvisol.

- The prolonged storage of the studied loamy sand Fluvisol under drought conditions substantially increased the potential bioavailability of Am. Redistribution of americium from the residual to all other fractions was established. Continuous freezing also provoked a slight increase of the potential mobility of americium.

- Five months storage of Cambisol soil at $14-20^{\circ} \mathrm{C}$ and $30-50 \%$ soil moisture has led to mobilization and redistribution of Am in comparison to one month storage, namely reduction of the residual Am and increase of carbonate and organicbound Am. Continuous soil drought and freezing of the sandy loam soil resulted in significant immobilization of Am (over 60\% of Am was found in the residual fraction).

Irrespective of the soil type after longer storage the organic-bound Am increased in both soils.

The above results indicated the risk of increased mobility and bioavailability of americium in the soil with acidic $\mathrm{pH}$, very low $\mathrm{CEC}$ and high sand content, under the examined extreme conditions. The Cambisol with higher $\mathrm{pH}, \mathrm{CEC}$ and clay content tended to immobilize americium at freeze and drought storage.

\section{Acknowledgements}

The authors gratefully acknowledge the financial support of the National Science Fund, Ministry of Education, Youth and Science of Bulgaria, Contract No. DDVU 02-60/2010.

\section{References}

Almas, A., B.R. Singh, B. Salbu 1999: Mobility of cadmium-109 and zinc-65 in soil influenced by equilibration time, temperature, and organic matter. - Journal of Environmental Quality, 28, pp. $1742-1750$

Alonso, U., C. Degueldre 2003: Modelling americium sorption onto colloids: effect of redox potential. - Colloids and Surfaces A: Physicochemical and Engineering Aspects, 217, pp. 55-62.

Borch, T., R. Kretzschmar, A. Kappler, V.P. Cappellen, M. Ginder-Vogel, A. Voegelin, K. Campbell 2010: Biochemical Redox Processes and their Impact on Contaminant Dynamics. Environmental Science and Technology, 44, pp. 15-23.

Brady, N., R. Weil 2002: The Nature and Properties of Soils. - Prentice Hall, 960 p.

Cantrell, K.J., A.R. Felmy 2012: Plutonium and Americium Geochemistry at Hanford: A Site-Wide Review. - Pacific Northwest National Laboratory Richland, 88 p.

FAO 2006: World reference base for soil resources. A framework for international classification correlation and communication. World Soil Resources Report 103. - Food and Agriculture Organization of the United Nations, Rome, $128 \mathrm{p}$. 
Igwe, J.C., I.C. Nnorom, B.C. Gbaruko 2005: Kinetics of radionuclides and heavy metals behaviour in soils: Implications for plant growth. - African Journal of Biotechnology, 4, pp. 1541-1547.

Koch-Steidl, H., G. Pröhl 2001: Considerations on the behaviour of long-lived radionuclides in the soil. - Radiation and Environmental Biophysics, 40, pp. 93-104.

Kovacheva, P., R. Djingova: Influence of freezing on the physicochemical forms of natural and technogenic radionuclides in Chernozem soil. - Chemical Papers (in press).

Kovacheva, P., S. Mitsiev, R. Djingova: Physicochemical fractionation of Americium, Thorium and Uranium in Chernozem soil after sharp temperature change and soil drought. - Chemical Papers, DOI: 10.2478/s11696-013-0457-y (in press).

Lehrsch, G.A., R.E. Sojka, D.L. Carter, P.M. Jolley 1991: Freezing effects on aggregate stability affected by texture, mineralogy, and organic matter. - Soil Science Society of America Journal, 55, pp. 1401-1406.

Marion, G.M. 1995: Freeze-thaw processes and soil chemistry. Special report 95-12. - U.S. Army Corps of Engineers, Cold Regions Research and Engineering Laboratory, $23 \mathrm{p}$.

Müller-Lupp, W., M. Bölter 2003: Effect of soil freezing on physical and microbiological properties of permafrost-affected soils. - In: Phillips, M., S. Springman, L. Arenson (Eds): 8th International Conference on Permafrost, Proceedings. Swets and Zeitlinger, pp. 801-805.

Rao, C.R.M., A. Sahuquillo, J.F. Lopez Sanchez 2008: A review of the different methods applied in environmental geochemistry for single and sequential extraction of trace elements in soils and related materials. - Water Air and Soil Pollution, 189, pp. 291-333.

Roussel-Debet, S., S. Deneux-Mustin, C. Munier-Lamy 2005: Screening the importance of soilorganisms on the radionuclides mobility. - Radioprotection, 40, pp. S87-S91.

Schultz, M.K., W.C. Burnett, K.G.W. Inn 1998: Evaluation of a sequential extraction method for determining actinide fractionation in soils and sediments. - Journal of Environmental Radioactivity, 40, pp. 155-174.

Wong, S.C., X.D. Li, G. Zhang, S.H. Qi, Y.S. Min 2002: Heavy metals in agricultural soils of the Pearl River Delta, South China. - Environmental Pollution, 119, pp. 33-44. 